\title{
Functional brown adipose tissue limits cardiomyocyte injury and adverse remodeling in catecholamine-induced cardiomyopathy
}

\section{Citation}

Thoonen, Robrecht, Laura Ernande, Juan Cheng, Yasuko Nagasaka, Vincent Yao, Alexandre Miranda-Bezerra, Chan Chen, et al. 2015. Functional Brown Adipose Tissue Limits Cardiomyocyte Injury and Adverse Remodeling in Catecholamine-Induced Cardiomyopathy. Journal of Molecular and Cellular Cardiology 84: 202-211. doi:10.1016/j.yjmcc.2015.05.002.

\section{Published Version}

doi:10.1016/j.yjmcc.2015.05.002

\section{Permanent link}

http://nrs.harvard.edu/urn-3:HUL.InstRepos:29729434

\section{Terms of Use}

This article was downloaded from Harvard University's DASH repository, and is made available under the terms and conditions applicable to Open Access Policy Articles, as set forth at http:// nrs.harvard.edu/urn-3:HUL.InstRepos:dash.current.terms-of-use\#OAP

\section{Share Your Story}

The Harvard community has made this article openly available.

Please share how this access benefits you. Submit a story.

Accessibility 


\section{Abstract}

Brown adipose tissue (BAT) has well recognized thermogenic properties mediated by uncoupling protein 1 (UCP1); more recently, BAT has been demonstrated to modulate cardiovascular risk factors. To investigate whether BAT also affects myocardial injury and remodeling, UCP1deficient $\left(\mathrm{UCP}^{-/-}\right)$mice, which have dysfunctional BAT, were subjected to catecholamineinduced cardiomyopathy. At baseline, there were no differences in echocardiographic parameters, plasma cardiac troponin I (cTnI) or myocardial fibrosis between wild-type (WT) and UCP1 $1^{-/-}$ mice. Isoproterenol infusion increased $\mathrm{cTnI}$ and myocardial fibrosis and induced left ventricular (LV) hypertrophy in both $\mathrm{WT}$ and $\mathrm{UCP} 1^{-/}$mice. $\mathrm{UCP} 1^{-/-}$mice also demonstrated exaggerated myocardial injury, fibrosis, and adverse remodeling, as well as decreased survival. Transplantation of WT BAT to $\mathrm{UCP}^{-/-}$mice prevented the isoproterenol-induced $\mathrm{cTnI}$ increase and improved survival, whereas $\mathrm{UCP} 1^{-/}$BAT transplanted to either $\mathrm{UCP} 1^{-/-}$or WT mice had no effect on cTnI release. After 3 days of isoproterenol treatment, phosphorylated AKT and ERK were lower in the LV's of UCP1 ${ }^{-/-}$mice than in those of WT mice. Activation of BAT was also noted in a model of chronic ischemic cardiomyopathy, and was correlated to LV dysfunction. Deficiency in UCP1, and accompanying BAT dysfunction, increases cardiomyocyte injury and adverse LV remodeling, and decreases survival in a mouse model of catecholamine-induced cardiomyopathy. Myocardial injury and decreased survival are rescued by transplantation of functional BAT to $\mathrm{UCP} 1^{-/}$mice,

\footnotetext{
(C) 2015 Elsevier Ltd. All rights reserved.

"Corresponding author at: Cardiac Ultrasound Laboratory, Massachusetts General Hospital, 55 Fruit Street, Boston, MA 02114, USA. Tel.: +1 617 726 7686; fax: +1 617726 8383. marielle@crosbie.com (M. Scherrer-Crosbie).

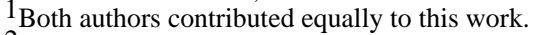

${ }^{2}$ Deceased.

Disclosures

None.
} 
suggesting a systemic cardioprotective role of functional BAT. BAT is also activated in chronic ischemic cardiomyopathy.

\section{Keywords}

Brown adipose tissue; Uncoupling protein 1; Isoproterenol; Cardioprotection; Heart failure

\section{Introduction}

Cardiomyocyte injury leading to cardiac remodeling and subsequent progression to heart failure represents a major cause of human morbidity and mortality [1]. To maintain adequate cardiac output in the face of decreased ventricular pump function, reflex pathways including the sympathetic nervous system are activated, in turn leading to increased catecholamine release from the heart and endocrine tissues. This exposure to excess catecholamines increases cardiomyocyte death and augments myocardial adverse remodeling [2].

Sympathetic nervous system activation and norepinephrine release [3], concomitant with the release of natriuretic peptides [4] occur after myocardial injury and during the development of adverse left ventricular (LV) remodeling. Interestingly, these molecules are also major contributors to the growth and stimulation of brown adipose tissue (BAT) [5,6]. Brown adipose tissue, a relatively sparse brownish-colored adipose tissue well recognized in rodents and children, has recently been detected in adult humans [7-9]. Upon activation of BAT, the brown adipocytes consume glucose and lipids and convert the energy from free fatty acids and glucose oxidation into heat (thermogenesis) [10]. The unique metabolic and thermogenic properties of BAT have generated substantial research interest in exploring its potential therapeutic applications for obesity and type II diabetes $[6,11,12]$.

The thermogenic capacity of BAT is mediated by the mitochondrial proton transporter uncoupling protein 1 (UCP1), which disperses the proton motive force generated by oxidative phosphorylation, generating heat as a by-product of this futile cycle [13]. Mice deficient in UCP1 (UCP1 $1^{-/}$mice) display impaired activation of BAT in response to cold and beta-adrenergic agonists, characterized by a mildly decreased thermogenic capacity [14,15], and reduced local blood flow [16].

Recently, several lines of evidence indicated that BAT and related tissues are capable of modulating several endocrine and cardiovascular risk factors. BAT activation or transplantation normalized both glucose tolerance and insulin resistance in obese or old mice $[17,18]$. Moreover, the beneficial effect on glucose metabolism was also extended to humans: in healthy volunteers Chondronikola et al. demonstrated that activated BAT increased insulin sensitivity [19]. In addition, perivascular and epicardial adipose tissue depots, which share characteristics of BAT [20], are implicated in the modulation of atherosclerosis and blood pressure [21].

Although BAT may be activated after myocardial injury and during ventricular remodeling, whether this activation has an effect on these processes is unknown. The objectives of the present study were to evaluate whether BAT was activated after myocardial injury and 
whether this activation was cardioprotective. To approach this question we first used a model of cardiac injury in which the activation of BAT is well recognized. The model we chose, chronic catecholamine (isoproterenol) exposure, leads to cardiac injury and cardiomyopathy [22]. Using this model, we compared the cardiac response of wild-type (WT) and $\mathrm{UCP}^{-/-}$mice (with functional and dysfunctional BAT respectively). In a series of separate experiments, we then investigated whether BAT was also activated in a clinically translatable model of ischemic cardiomyopathy.

\section{Material and methods}

Additional material and methods are detailed in the Supplemental Data.

\subsection{Experimental animals}

All animal procedures were conducted in accordance with guidelines published in the Guide for the Care and Use of Laboratory Animals (National Research Council, National Academy Press, Washington, DC, 1996) and were approved by the Massachusetts General Hospital Subcommittee on Research Animal Care. C57B16/J WT mice were obtained from Jackson Laboratory (Bar Harbor, ME). Whole body UCP1 knockout mice (UCP1 ${ }^{-/}$) mice, as described in Enerbäck et al. [15], were obtained courtesy of Dr. Randall Mynatt (Pennington Biomedical Research Center, Baton Rouge, LA) and were bred at Massachusetts General Hospital. All mice were housed at thermoneutrality $\left(31^{\circ} \mathrm{C}\right)$ at all times and were studied at the age of $12-14$ weeks.

\subsection{Experimental protocol}

All experimental groups are summarized in Fig. 1. Alzet osmotic minipumps (no. 1002; Alza Durect Corp., Mountain View, CA, USA) containing isoproterenol (60 mg/kg/d) [23] or saline were subcutaneously and dorsally inserted in mice under isoflurane anesthesia. Cardiomyocyte injury, gene expression levels and immunoblots were measured 3 days after the start of the infusion, and myocardial fibrosis after 14 days. Echocardiographic measurements and blood pressure were measured at baseline and after 14 days of saline or isoproterenol infusion. Metabolic parameters were obtained at baseline after $16 \mathrm{~h}$ of fasting.

Brown adipose tissue transplantation was performed as described previously [18]. Mice were allowed to recover for 8 weeks before saline or isoproterenol infusion was started.

Myocardial infarction (MI) was studied in WT mice only and was produced by ligation of the left anterior descending coronary artery, as previously described [24]. The mice were sacrificed 8 weeks after the procedure.

\subsection{Echocardiography}

Transthoracic echocardiography was performed as described [25, 26]. LV end-diastolic diameter (LVEDD), fractional shortening (FS), anterior wall thickness (AWT) and posterior wall thickness (PWT) were obtained from M-mode tracings at the level of the papillary muscles. The thickness to radius ratio [27], H/R, was calculated. In the MI model, the LV ejection fraction (LVEF) was calculated as previously described [28]. 


\subsection{Non-invasive blood pressure measurements}

Systolic (SBP) and diastolic blood pressure (DBP) were measured non-invasively in awake mice by tail-cuff (MC4000MSP, Hatteras Instruments, Inc.) [29].

\subsection{Collection and analysis of blood and plasma}

Mice were either fed (for cardiomyocyte injury measurement by plasma cardiac troponin I (cTnI), fatty acid binding protein 3 (FABP3) and myosin light chain 3 (Myl3) [30]) or fasted for $16 \mathrm{~h}$ (for glucose, triglyceride and insulin measurements) and anesthetized with isoflurane for facial vein puncture. Glucose and insulin tolerance tests (GTT and ITT) were performed as previously described [31].

\subsection{Tissue analysis}

To assess the degree of LV fibrosis, sections were stained with PicroSirius red. The ratio of collagen deposition (including perivascular collagen) to total myocardial area was quantified (IP Lab Spectrum; Signal Analytics, Vienna, VA) as described [32].

The mRNA expression levels were measured in LV and BAT as previously described [33], with specific primer-probe sets for UCP1, UCP2 and UCP3 (Mm00494069_m1, Mm00627599_m1, Mm00494077_m1, respectively, Life Technologies) and specific primer sets for housekeeping genes RPL13a, ACTB and 18S rRNA (see supplemental data for specifics). Antibodies for the immunoblots included P-ERK1/2, ERK1/2, P-AKT and AKT (Cell Signaling Technologies, all used at a dilution of 1:1000).

\subsection{Statistical analysis}

Data are expressed as mean \pm SEM. To compare serial echocardiographic parameters and blood pressure measurements, we used a two-way ANOVA for repeated measurements. If the interaction of time and genotype was significant, unpaired Student's t-tests were used to compare parameters between genotypes. For the analysis of changes over time, paired Student t-tests were used. To compare cardiac biomarkers and molecular biology parameters, one- or two-way ANOVA were used, as appropriate. Linear regression analysis was used to determine the correlation coefficient $\left(\mathrm{r}^{2}\right)$ between BAT activation estimated by UCP1 mRNA levels and LVEF after MI. In all experiments, $\mathrm{P}<0.05$ was considered significant. The analyses were performed using Prism 6.0f for Mac (GraphPad Software, La Jolla, California, USA, www.graphpad.com).

\section{Results}

\subsection{Adverse LV remodeling after catecholamine exposure is aggravated in $\mathrm{UCP1}{ }^{-/}-$mice}

At baseline, LV dimensions and fractional shortening were similar in WT and $\mathrm{UCP} 1^{-/-}$mice for both genders (Fig. 2 and Table 1 for males, Table S1 for females). Isoproterenol infusion for 14 days induced LV concentric hypertrophy (increases in wall thickness, H/R, LV mass) in both WT and $\mathrm{UCP}^{-/-}$mice (Fig. 2A-C, Tables $1, \mathrm{~S} 1$ ), detected both by echocardiography and at necropsy. However, isoproterenol induced greater hypertrophy in both male and female UCP1 ${ }^{-/-}$mice than in WT mice (Fig. 2A-C, Tables 1, S1). The LV 
fractional shortening of male $\mathrm{UCP}^{-/-}$mice decreased after isoproterenol infusion whereas it did not in male WT mice (Fig. 2D, Table 1).

Differences in the isoproterenol-induced remodeling between genders were observed. The impairment in LV fractional shortening was not detected in female mice (Table S1). In addition, after 14 days of isoproterenol infusion a reduction in LV cavity dimensions was observed in female $\mathrm{UCP} 1^{-/}$mice whereas LV cavity dimensions did not change in WT female mice or in male mice (Tables $1, \mathrm{~S} 1$ ).

Thus, genetic disruption of UCP1 expression predisposes the myocardium to greater adverse remodeling in both genders.

\subsection{UCP1-deficiency increases fibrosis in catecholamine-induced cardiomyopathy}

Analysis of PicroSirius red-stained histological sections revealed virtually no collagen deposition in WT (Fig. 2E) or UCP1 ${ }^{-/-}$mice (Fig. 2G) after saline. Fourteen days of isoproterenol infusion induced a significant increase of myocardial fibrosis in WT (Fig. 2F) and $\mathrm{UCP}^{-/-}$mice (Fig. $2 \mathrm{H}$ ). The amount of isoproterenol-induced fibrosis was higher in $\mathrm{UCP}^{-1-}$ mice than in WT mice $(14 \pm 4 \%$ vs. $2 \pm 1 \%$, p < 0.001, Fig. $1 \mathrm{I})$.

\subsection{UCP1-deficiency increases myocardial injury in catecholamine-induced cardiomyopathy}

Consistent with increased fibrosis, potentially indicating enhanced cardiomyocyte injury and death in $\mathrm{UCP}^{-/-}$mice after 14-day isoproterenol treatment, continuous 3-day isoproterenol treatment induced a significantly greater increase in plasma cardiac troponin I (cTnI) levels in $\mathrm{UCP} 1^{-/-}$versus WT mice $(6.3 \pm 1.5$ fold, $\mathrm{P}<0.0001$; Fig. 3A). Additional plasma markers of cardiac injury (FABP3, Fig. 3B and Myl3, Fig. 3C) followed similar patterns, indicating a greater degree of cardiomyocyte injury in $\mathrm{UCP}^{-/-}$mice. These data suggest that UCP1 limits catecholamine-induced cardiomyocyte injury.

\subsection{Decreased survival after catecholamine administration in $\mathrm{UCP} 1^{-/-}$mice}

The survival of $\mathrm{UCP} 1^{-/-}$mice after 14 days of isoproterenol was lower than that of WT mice (30/35 (85\%) WT and 21/35 (60\%) UCP1 $1^{-/-}$mice, p < 0.01) (Fig. 3D), suggesting a protective effect of UCP1 against isoproterenol-induced death.

\subsection{Effects of isoproterenol treatment on gene expression levels of UCP1, UCP2 and UCP3 in BAT and LV of WT and UCP1-/- mice}

Three days of isoproterenol infusion induced a 5-fold increase in UCP1 mRNA levels in BAT of WT mice, indicative of BAT activation (Fig. 4A). Expression levels of UCP2 were similar in WT and $\mathrm{UCP} 1^{-1-}$ BAT treated with saline and increased similarly with 3 days of isoproterenol (Fig. 4B). The expression levels of UCP3 were comparable between WT and $\mathrm{UCP}^{-/-}$treated with saline, but decreased in $\mathrm{UCP} 1^{-/-}$after isoproterenol (Fig. 4C). These data indicate that $\mathrm{UCP} 1^{-/-}$mice do not seem to compensate the loss of UCP1 by increasing the expression of UCP2 or UCP3 in BAT. 
In contrast to the high levels of UCP1 mRNA in WT BAT, UCP1 expression was not detected in the $\mathrm{LV}$ of WT and $\mathrm{UCP} 1^{-/-}$mice, both with saline and with 3 days of isoproterenol (Fig. 4A). In the LV, no differences were observed in mRNA expression levels of $\mathrm{UCP} 2$ in WT and $\mathrm{UCP}^{-/}$mice with saline. However, isoproterenol increased the expression levels of LV UCP2 mRNA in UCP1 $1^{-/}$mice (Fig. 4B). UCP3 levels were comparable in the $\mathrm{LV}$ of WT and $\mathrm{UCP} 1^{-/-}$treated with saline, and decreased similarly with isoproterenol (Fig. 4C). These data suggest that the LV does not express UCP1 mRNA and that the only difference between WT and $\mathrm{UCP} 1^{-/-}$animals is an increase in the gene expression levels of $\mathrm{UCP} 2$ in $\mathrm{UCP} 1^{-/-}$mice after isoproterenol.

\subsection{The effect of isoproterenol on blood pressure is similar in WT and UCP1-/- mice}

Wild-type and $\mathrm{UCP}^{-/-}$mice had a similar BP at baseline. Isoproterenol-infusion for 14 days induced a similar increase in BP in both genotypes (Figure S1). These findings suggest that the differences in cardiac remodeling are not caused by differences in blood pressure.

\subsection{Metabolic parameters of WT and UCP1-/- mice at the age of 12-16 weeks}

There were no differences between WT and $\mathrm{UCP} 1^{-/-}$mice in body weight (Fig. 4A), plasma glucose (Fig. 5B), insulin (Fig. 5C), and triglycerides (Fig. 5D) levels in mice fasted for 16 h. However $\mathrm{UCP} 1^{-/-}$mice demonstrated mildly impaired glucose tolerance after a bolus glucose injection and glucose recovery after insulin injection (Fig. 5E-F). Therefore, mild metabolic abnormalities are noted in the $\mathrm{UCP} 1^{-/-}$mice.

\subsection{Transplantation of functional BAT in UCP1-/- mice limits cardiomyocyte injury and reduces mortality in catecholamine-induced cardiomyopathy}

To determine whether the presence of functional BAT reverses the increased cardiac injury observed in $\mathrm{UCP}^{-/-}$mice, BAT transplantations were performed. At 8 weeks, glucose tolerance was lower in $\mathrm{UCP}^{-/-}$mice receiving $\mathrm{UCP}^{-/-} \mathrm{BAT}$ transplants compared to WT mice receiving $\mathrm{UCP} 1^{-/-}$BAT transplants, and increased by transplantation of WT BAT to $\mathrm{UCP}^{-1-}$ mice (Fig. 6A). These results demonstrate that transplantation of functional BAT into the visceral cavity of $\mathrm{UCP}^{-/-}$mice improves whole-body glucose homeostasis.

Transplanted WT and $\mathrm{UCP}^{-/-}$mice were infused continuously with isoproterenol or saline for 3 days and then plasma cTnI was measured. cTnI levels were markedly increased in the $\mathrm{UCP}^{-1-}$ mice transplanted with $\mathrm{UCP}^{-/-} \mathrm{BAT}$ compared to WT mice transplanted with $\mathrm{UCP}^{-/-}$BAT and $\mathrm{UCP}^{-/-}$mice transplanted with WT BAT (Fig. 6B). The levels of cTnI in the mice transplanted with $\mathrm{UCP}^{-/-} \mathrm{BAT}$ were similar to those of non-transplanted mice of the same strain. Importantly, no difference in cTnI levels was observed between UCP1 ${ }^{-/}$ mice transplanted with WT BAT and WT mice transplanted with UCP1 ${ }^{-1-}$ BAT (Fig. 5B), indicating that transplantation of functional WT BAT protects against catecholamineinduced cardiomyocyte injury in vivo. Interestingly, mortality following isoproterenol stress was higher in the $\mathrm{UCP}^{-/-}$mice transplanted with $\mathrm{UCP}^{-/-} \mathrm{BAT}$ compared to all the other transplantation groups (Fig. 6C). These findings suggest that BAT remotely mediates cardioprotection and protects against the isoproterenol-stress induced mortality. 


\subsection{UCP1-deficiency limits the activation of cardioprotective signaling pathways during catecholamine exposure}

Western blots revealed that WT and $\mathrm{UCP} 1^{-1-}$ mice have a similar degree of AKT (Fig. 7A) and ERK1/2 (Fig. 7B) phosphorylation in the LV after saline. After 3 days of isoproterenol infusion, phosphorylation of AKT (Fig. 7A) was unchanged in the WT and decreased in the $\mathrm{UCP}^{-1-}$ mice compared to saline. In contrast, isoproterenol treatment was associated with an increase in phosphorylation of ERK1/2 in WT but not UCP1 ${ }^{-/-}$mice (Fig. 7B). Thus, cardioprotective signaling mechanisms through AKT might be attenuated in $\mathrm{UCP}^{-/-}$mice while cardioprotective signaling through ERK1/2 are not activated in $\mathrm{UCP}^{-/-}$mice after catecholamine-induced cardiomyocyte injury.

\subsection{BAT is activated in ischemic cardiomyopathy}

BAT gene expression levels of UCP1 in WT mice were higher eight weeks after myocardial infarction (MI) induced by left coronary artery ligation, than 8 weeks after sham intervention (Fig. 8A). At the same time point, BAT weight was greater in mice after MI than after sham operation $(203 \pm 22 \mathrm{mg}$ vs. $131 \pm 7 \mathrm{mg}, \mathrm{p}=0.02)$. Additionally, the expression level of UCP1 was correlated to the degree of cardiac dysfunction, ascertained by echocardiographic LVEF (Fig. 8B) $\left(\mathrm{r}^{2}=0.4052, \mathrm{p}<0.001\right)$. These data demonstrate that BAT is activated after MI, and that the activation is related to the degree of LV dysfunction.

\section{Discussion}

The present study provides the first experimental evidence that functional BAT remotely protects against cardiomyocyte injury and maladaptive remodeling in vivo. Although previous studies have suggested a potential role for BAT and BAT-secreted factors in regulating cardiovascular risk factors $[6,17]$ no study has addressed the ability of BAT to protect cardiomyocytes.

Our results suggest that the absence of UCP1 is associated with increased cardiomyocyte injury and cardiac remodeling in a model of catecholamine-induced cardiomyopathy. The detection of higher levels of cTnI, an early marker of cardiomyocyte injury [30], in the plasma of UCP1 $1^{-/}$mice compared to WT mice, and the reversal of this difference by WT BAT transplantation, suggest that the presence of functional BAT protects cardiomyocytes against catecholamine-induced injury. A cardioprotective local effect of cardiac UCP1 expressing cells is highly unlikely as QPCR analysis using highly sensitive and specific taqman probes did not reveal any UCP1 expression in the mouse LV, a finding that confirms previous analysis in rodents [34]. Uncoupling proteins 2 and 3 are expressed in the heart and UCP2 has been shown to decrease cardiomyocyte death [35]. However, a decrease in cardiac UCP2 in UCP1 ${ }^{-/-}$mice that would increase cardiomyocyte injury after isoproterenol is unlikely based on the increase in mRNA observed in this strain. An increase in UCP3 has recently been implicated in the decreased efficiency of diabetic hearts post ischemiareperfusion [36]; such an increase in $\mathrm{UCP}^{-/-}$mice is also unlikely as UCP3 mRNA is robustly decreased after isoproterenol infusion in this strain. 
$\mathrm{UCP} 1^{-1-}$ mice were found to have a substantial increase in collagen deposition compared to WT mice after isoproterenol. In isoproterenol infusion models, myocardial fibrosis has been closely related to the amount of myocardial necrosis [37]. Thus, the increased fibrosis is most likely due to the increased cardiomyocyte injury. Finally, a more pronounced concentric hypertrophic remodeling of the $\mathrm{LV}$ following isoproterenol infusion was observed in $\mathrm{UCP} 1^{-/-}$mice; this effect could be due to the absence of a direct antihypertrophic effect of BAT or to a secondary response to the increased fibrosis. In male $\mathrm{UCP}^{-/-}$mice, the maladaptive remodeling was accompanied by a decrease in LV systolic function, whereas in female $\mathrm{UCP} 1^{-/}$mice, increased concentric hypertrophy was noted. Similar gender differences in LV remodeling have been described previously in murine $[38,39]$ and human $[40]$ models of MI and pressure-overload and may be due to the role of estrogens.

The survival of $\mathrm{UCP}^{-/-}$mice after isoproterenol infusion was lower than that of WT mice. The deaths mostly occurred within the first 5 days after the start of the infusion. Based on our echocardiographic data, it is unlikely that the observed deaths are due to heart failure, as the drop in LVEF was modest. Similarly, we did not observe a marked increase in the blood pressure of $\mathrm{UCP}^{-/-}$mice that could explain an increase in mortality. One potential mechanism explaining the decreased survival of $\mathrm{UCP}^{-/-}$mice could involve larger clusters of necrotic cells that would provide more arrhythmogenic foci in the $\mathrm{UCP} 1^{-/-}$mice.

Isoproterenol infusion for three days was associated with an increase in the phosphorylation of ERK1/2 in WT mice, but not in UCP1 ${ }^{-/-}$mice. Additionally, the phosphorylation of AKT was decreased in $\mathrm{UCP} 1^{-/}$mice after isoproterenol whereas it was unchanged in WT. Both ERK1/2 and AKT have been implicated as cardioprotective pathways in ischemiareperfusion injury [41,42]. Activation of ERK1/2 decreases the opening of the mitochondrial permeability transition pore [43], and inhibits apoptotic pathways in cardiomyocytes [44]. The Pi3K-AKT pathway has long been recognized as one of the most potent pro-survival pathways in the heart and activates potent anti-apoptotic signaling pathways in cardiomyocytes [42,45]. Intrinsic states of AKT phosphorylation have been shown to determine cell fate after different myocardial insults. A deficiency in the phosphorylation of AKT, as seen in our data, is generally detrimental for cardiomyocyte survival [45].

Our data indicate that BAT exerts a systemic action that results in a cardioprotective mechanism. Recently, the endocrine potential of BAT has generated research interest [46]. Several signaling molecules with endocrine properties are released by BAT, especially when activated [18,47-49]. The endocrine properties of BAT are relevant in physiological processes. For example, experimental BAT transplantation has been shown to improve glucose tolerance and insulin sensitivity, through an increase in interleukin 6 [18]. The heart is a potential target of adipokines synthetized in BAT such as FGF21; FGF21 demonstrated cardiac antihypertrophic effects [50], and a recent study reported cardioprotective effects of FGF21 in a mouse model of experimental MI [51]. Therefore, it is possible that BAT secretes an adipokine with direct cardioprotective signaling properties in the heart. It is less likely that BAT from $\mathrm{UCP}^{-/-}$mice would secrete a cardiotoxic adipokine since the levels of cTnI from WT and $\mathrm{UCP}^{-/-}$mice transplanted with $\mathrm{UCP} 1^{-/-}$BAT were similar to those of untransplanted mice before and after isoproterenol. 
Alternatively, BAT activity is correlated to overall improvements in metabolism and hence, improved glucose and insulin handling [17, 18]. Although the metabolic abnormalities detected in the $\mathrm{UCP} 1^{-/-}$mice in our study were modest, the mild glucose intolerance may still negatively impact cardioprotection. Interestingly, however, several studies have noted that diabetes decreased rather than increased the amount of necrosis in catecholamineinduced injury, maybe due to desensitization to the catecholamine effects [52-54]. Of note, one limitation of the present study is that the functional consequences of the limitation of cardiac injury by BAT transplantation were not investigated.

Brown adipose tissue is activated and cardioprotective in a model of catecholamine-induced cardiomyopathy that attempts to reproduce the high levels of catecholamines present in heart failure. Such high levels of catecholamines, however, are infrequent. It is therefore noteworthy that BAT is also activated after MI and that the activation was correlated to the degree of LV dysfunction. Whether BAT is cardioprotective after MI or in other models of heart failure should be further studied.

In humans, Chondronikola et al. [19] have recently demonstrated that the presence of functional BAT does improve insulin sensitivity. Brown adipose tissue or brown adipocyte transplantation has been suggested as a potential therapy of obesity [11] and has become more attainable as the culture of human brown adipocytes has been achieved [7]. Thus, it is conceivable, if BAT shows further promises as a cardioprotective tissue, that it may be applied in humans.

In conclusion, in catecholamine-induced cardiomyopathy, activated BAT decreases myocardial injury, fibrosis, and LV adverse remodeling through a systemic effect. This cardioprotective effect could be due to secreted substances (so-called batokines) or occur through systemic improvements in metabolism. If such a cardioprotective effect can be extended to other models of heart failure, BAT activation or transplantation may show promise as novel therapeutic avenues.

\section{Supplementary Material}

Refer to Web version on PubMed Central for supplementary material.

\section{Acknowledgments}

Funding

This work was supported by grant R21-DK092909 and a SPARK award from the Massachusetts General Hospital (both to M.S-C.) and a training grant from the French Federation of Cardiology (to L.E.)

\section{Abbreviations}

$\begin{array}{ll}\text { BAT } & \text { brown adipose tissue } \\ \text { UCP1 } & \text { uncoupling protein 1 } \\ \text { UCP1 }^{-/-} & \text {UCP1-deficient }\end{array}$


LV left ventricle

WT wild-type

H/R wall thickness/LV radius

LVMI LV mass index

cTnI cardiac troponin I

MI myocardial infarct

LVEDD LV end-diastolic diameter

LVESD LV end-systolic diameter

PWT posterior wall thickness

IVS interventricular septal thickness

AWT anterior wall thickness

LVEF LV ejection fraction

SBP systolic blood pressure

DBP diastolic blood pressure

GTT glucose tolerance test

ITT insulin tolerance test

FABP3 fatty acid binding protein 3

MYL3 myosin light chain 3

\section{Appendix A. Supplementary data}

Supplementary data to this article can be found online at http://dx.doi.org/10.1016/j.yjmcc. 2015.05.002.

\section{References}

1. Mozaffarian D, Benjamin EJ, Go AS, Arnett DK, Blaha MJ, Cushman M, et al. Heart disease and stroke statistics-2015 update. A report from the American Heart Association. Circulation. 2014; 131:e152-e322. [CIR].

2. Baker AJ. Adrenergic signaling in heart failure: a balance of toxic and protective effects. Pflugers Arch. 2014; 466:1139-1150. [PubMed: 24623099]

3. Manfrini O, Morgagni G, Pizzi C, Fontana F, Bugiardini R. Changes in autonomic nervous system activity: spontaneous versus balloon-induced myocardial ischaemia. Eur Heart J. 2004; 25:15021508. [PubMed: 15342169]

4. Sabatine MS, Morrow DA, de Lemos JA, Omland T, Desai MY, Tanasijevic M, et al. Acute changes in circulating natriuretic peptide levels in relation to myocardial ischemia. J Am Coll Cardiol. 2004; 44:1988-1995. [PubMed: 15542281]

5. Bordicchia M, Liu D, Amri E-Z, Ailhaud G, Dessì-Fulgheri P, Zhang C, et al. Cardiac natriuretic peptides act via p38 MAPK to induce the brown fat thermogenic program in mouse and human adipocytes. J Clin Invest. 2012; 122:1022-1036. [PubMed: 22307324] 
6. Collins S. A heart-adipose tissue connection in the regulation of energy metabolism. Nat Rev Endocrinol. 2014; 10:157-163. [PubMed: 24296515]

7. Cypess AM, White AP, Vernochet C, Schulz TJ, Xue R, Sass CA, et al. Anatomical localization, gene expression profiling and functional characterization of adult human neck brown fat. Nat Med. 2013; 19:635-639. [PubMed: 23603815]

8. van Marken Lichtenbelt WD, Vanhommerig JW, Smulders NM, Drossaerts JMAFL, Kemerink GJ, Bouvy ND, et al. Cold-activated brown adipose tissue in healthy men. N Engl J Med. 2009; 360:1500-1508. [PubMed: 19357405]

9. Saito M, Okamatsu-Ogura Y, Matsushita M, Watanabe K, Yoneshiro T, Nio-Kobayashi J, et al. High incidence of metabolically active brown adipose tissue in healthy adult humans: effects of cold exposure and adiposity. Diabetes. 2009; 58:1526-1531. [PubMed: 19401428]

10. Cannon B, Nedergaard J. Brown adipose tissue: function and physiological significance. Physiol Rev. 2004; 84:277-359. [PubMed: 14715917]

11. Tseng Y-H, Cypess AM, Kahn CR. Cellular bioenergetics as a target for obesity therapy. Nat Rev Drug Discov. 2010; 9:465-482. [PubMed: 20514071]

12. Townsend K, Tseng Y-H. Brown adipose tissue: recent insights into development, metabolic function and therapeutic potential. Adipocytes. 2012; 1:13-24.

13. Nicholls DG, Locke RM. Thermogenic mechanisms in brown fat. Physiol Rev. 1984; 64:1-64. [PubMed: 6320232]

14. Meyer CW, Willershäuser M, Jastroch M, Rourke BC, Fromme T, Oelkrug R, et al. Adaptive thermogenesis and thermal conductance in wild-type and UCP1-KO mice. Am J Physiol Regul Integr Comp Physiol. 2010; 299:R1396-R1406. [PubMed: 20826705]

15. Enerbäck S, Jacobsson A, Simpson EM, Guerra C, Yamashita H, Harper ME, et al. Mice lacking mitochondrial uncoupling protein are cold-sensitive but not obese. Nature. 1997; 387:90-94. [PubMed: 9139827]

16. Baron DM, Clerté M, Brouckaert P, Raher MJ, Flynn AW, Zhang H, et al. In vivo non-invasive characterization of brown adipose tissue blood flow by contrast ultrasound in mice. Circ Cardiovasc Imaging. 2012; 5:652-659. [PubMed: 22776888]

17. Bartelt A, Bruns OT, Reimer R, Hohenberg H, Ittrich H, Peldschus K, et al. Brown adipose tissue activity controls triglyceride clearance. Nat Med. 2011; 17:200-205. [PubMed: 21258337]

18. Stanford KI, Middelbeek RJW, Townsend KL, An D, Nygaard EB, Hitchcox KM, et al. Brown adipose tissue regulates glucose homeostasis and insulin sensitivity. J Clin Invest. 2013; 123:215223. [PubMed: 23221344]

19. Chondronikola M, Volpi E, Børsheim E, Porter C, Annamalai P, Enerbäck S, et al. Brown adipose tissue improves whole-body glucose homeostasis and insulin sensitivity in humans. Diabetes. 2014; 63:4089-4099. [PubMed: 25056438]

20. Fitzgibbons TP, Czech MP. Epicardial and perivascular adipose tissues and their influence on cardiovascular disease: basic mechanisms and clinical associations. J Am Heart Assoc. 2014; 3 (e000582-2).

21. Chang L, Milton H, Eitzman DT, Chen YE. Paradoxical roles of perivascular adipose tissue in atherosclerosis and hypertension. Circ J. 2013; 77:11-18. [PubMed: 23207957]

22. Soonpaa MH, Field LJ. Assessment of cardiomyocyte DNA synthesis during hypertrophy in adult mice. Am J Physiol. 1994; 266:H1439-H1445. [PubMed: 8184922]

23. Nakayama H, Bodi I, Correll RN, Chen X, Lorenz J, Houser SR, et al. alpha1G-dependent T-type $\mathrm{Ca} 2+$ current antagonizes cardiac hypertrophy through a NOS3-dependent mechanism in mice. $\mathrm{J}$ Clin Invest. 2009; 119:3787-3796. [PubMed: 19920353]

24. Scherrer-Crosbie M, Steudel W, Ullrich R, Hunziker PR, Liel-Cohen N, Newell J, et al. Echocardiographic determination of risk area size in a murine model of myocardial ischemia. Am J Physiol. 1999; 277:H986-H992. [PubMed: 10484420]

25. Scherrer-Crosbie M, Ullrich R, Bloch KD, Nakajima H, Nasseri B, Aretz HT, et al. Endothelial nitric oxide synthase limits left ventricular remodeling after myocardial infarction in mice. Circulation. 2001; 104:1286-1291. [PubMed: 11551881] 
26. Kurtz B, Thibault HB, Raher MJ, Popovich JR, Cawley S, Atochin DN, et al. Nitric oxide synthase 3 deficiency limits adverse ventricular remodeling after pressure overload in insulin resistance. Am J Physiol Heart Circ Physiol. 2011; 301:H2093-H2101. [PubMed: 21856905]

27. Liu J, Rigel DF. Echocardiographic examination in rats and mice. Methods Mol Biol. 2009; 573:139-155. [PubMed: 19763926]

28. Rodrigues ACT, Hataishi R, Ichinose F, Bloch KD, Derumeaux G, Picard MH, et al. Relationship of systolic dysfunction to area at risk and infarction size after ischemia-reperfusion in mice. J Am Soc Echocardiogr. 2004; 17:948-953. [PubMed: 15337959]

29. Krege JH, Hodgin JB, Hagaman JR, Smithies O. A noninvasive computerized tail-cuff system for measuring blood pressure in mice. Hypertension. 1995; 25:1111-1115. [PubMed: 7737724]

30. Tonomura Y, Matsushima S, Kashiwagi E, Fujisawa K, Takagi S, Nishimura Y, et al. Biomarker panel of cardiac and skeletal muscle troponins, fatty acid binding protein 3 and myosin light chain 3 for the accurate diagnosis of cardiotoxicity and musculoskeletal toxicity in rats. Toxicology. 2012; 302:179-189. [PubMed: 22878004]

31. Raher MJ, Thibault HB, Buys ES, Kuruppu D, Shimizu N, Brownell A-L, et al. A short duration of high-fat diet induces insulin resistance and predisposes to adverse left ventricular remodeling after pressure overload. Am J Physiol Heart Circ Physiol. 2008; 295:H2495-H2502. [PubMed: 18978196]

32. Buys ES, Raher MJ, Blake SL, Neilan TG, Graveline AR, Passeri JJ, et al. Cardiomyocyterestricted restoration of nitric oxide synthase 3 attenuates left ventricular remodeling after chronic pressure overload. Am J Physiol Heart Circ Physiol. 2007; 293:H620-H627. [PubMed: 17416602]

33. Vandesompele J, De Preter K, Pattyn F, Poppe B, Van Roy N, De Paepe A, et al. Accurate normalization of real-time quantitative RT-PCR data by geometric averaging of multiple internal control genes. Genome Biol. 2002; 3 [RESEARCH0034].

34. Klaus S, Casteilla L, Bouillaud F, Ricquier D. The uncoupling protein UCP: a membraneous mitochondrial ion carrier exclusively expressed in brown adipose tissue. Int J Biochem. 1991; 23:791-801. [PubMed: 1773883]

35. Teshima Y, Akao M, Jones SP, Marbán E. Uncoupling protein-2 overexpression inhibits mitochondrial death pathway in cardiomyocytes. Circ Res. 2003; 93:192-200. [PubMed: 12855674]

36. Banke NH, Lewandowski ED. Impaired cytosolic NADH shuttling and elevated UCP3 contribute to inefficient citric acid cycle flux support of postischemic cardiac work in diabetic hearts. J Mol Cell Cardiol. 2015; 79:13-20. [PubMed: 25450611]

37. Benjamin IJ, Jalil JE, Tan LB, Cho K, Weber KT, Clark WA. Isoproterenol-induced myocardial fibrosis in relation to myocyte necrosis. Circ Res. 1989; 65:657-670. [PubMed: 2527639]

38. Montalvo C, Villar AV, Merino D, García R, Ares M, Llano M, et al. Androgens contribute to sex differences in myocardial remodeling under pressure overload by a mechanism involving TGF- $\beta$. PLoS One. 2012; 7:e35635. [PubMed: 22558184]

39. Wu JC, Nasseri BA, Bloch KD, Picard MH, Scherrer-Crosbie M. Influence of sex on ventricular remodeling after myocardial infarction in mice. J Am Soc Echocardiogr. 2003; 16:1158-1162. [PubMed: 14608287]

40. Villar AV, Llano M, Cobo M, Expósito V, Merino R, Martín-Durán R, et al. Gender differences of echocardiographic and gene expression patterns in human pressure overload left ventricular hypertrophy. J Mol Cell Cardiol. 2009; 46:526-535. [PubMed: 19639678]

41. Murphy E, Steenbergen C. Mechanisms underlying acute protection from cardiac ischemiareperfusion injury. Physiol Rev. 2008; 88:581-609. [PubMed: 18391174]

42. van Berlo JH, Maillet M, Molkentin JD. Signaling effectors underlying pathologic growth and remodeling of the heart. J Clin Invest. 2013; 123:37-45. [PubMed: 23281408]

43. Ping P, Zhang J, Cao X, Li RC, Kong D, Tang XL, et al. PKC-dependent activation of p44/p42 MAPKs during myocardial ischemia-reperfusion in conscious rabbits. Am J Physiol. 1999; 276:H1468-H1481. [PubMed: 10330229]

44. Cuadrado I, Fernández-Velasco M, Boscá L, Las Heras de B. Labdane diterpenes protect against anoxia/reperfusion injury in cardiomyocytes: involvement of AKT activation. Cell Death Dis. 2011; 2:e229. [PubMed: 22071634] 
45. Sussman MA, Völkers M, Fischer K, Bailey B, Cottage CT, Din S, et al. Myocardial AKT: the omnipresent nexus. Physiol Rev. 2011; 91:1023-1070. [PubMed: 21742795]

46. Villarroya J, Cereijo R, Villarroya F. An endocrine role for brown adipose tissue? Am J Physiol Endocrinol Metab. 2013; 305:E567-E572. [PubMed: 23839524]

47. Silva JE, Larsen PR. Potential of brown adipose tissue type II thyroxine 5 -deiodinase as a local and systemic source of triiodothyronine in rats. J Clin Invest. 1985; 76:2296-2305. [PubMed: 4077981]

48. Hondares E, Iglesias R, Giralt A, Gonzalez FJ, Giralt M, Mampel T, et al. Thermogenic activation induces FGF21 expression and release in brown adipose tissue. J Biol Chem. 2011; 286:1298312990. [PubMed: 21317437]

49. Virtue S, Feldmann H, Christian M, Tan CY, Masoodi M, Dale M, et al. A new role for lipocalin prostaglandin $\mathrm{d}$ synthase in the regulation of brown adipose tissue substrate utilization. Diabetes. 2012; 61:3139-3147. [PubMed: 22923471]

50. Planavila A, Redondo I, Hondares E, Vinciguerra M, Munts C, Iglesias R, et al. Fibroblast growth factor 21 protects against cardiac hypertrophy in mice. Nat Commun. 2013; 4:1-12.

51. Liu SQ, Roberts D, Kharitonenkov A, Zhang B, Hanson SM, Li YC, et al. Endocrine protection of ischemic myocardium by FGF21 from the liver and adipose tissue. Sci Rep. 2013; 3:2767.

[PubMed: 24067542]

52. Gøtzsche O. Lack of cardiotoxic effect of isoproterenol in streptozotocin diabetic rats. A morphometric study of isoproterenol induced fibrosis. Virchows Arch A Pathol Anat Histol. 1982; 397:83-91. [PubMed: 6755882]

53. Gøtzsche $\mathrm{O}$. The adrenergic beta-receptor adenylate cyclase system in heart and lymphocytes from streptozotocin-diabetic rats. In vivo and in vitro evidence for a desensitized myocardial betareceptor. Diabetes. 1983; 32:1110-1116. [PubMed: 6317497]

54. el-Hage AN, Herman EH, Jordan AW, Ferrans VJ. Influence of the diabetic state on isoproterenolinduced cardiac necrosis. J Mol Cell Cardiol. 1985; 17:361-369. [PubMed: 2991538] 

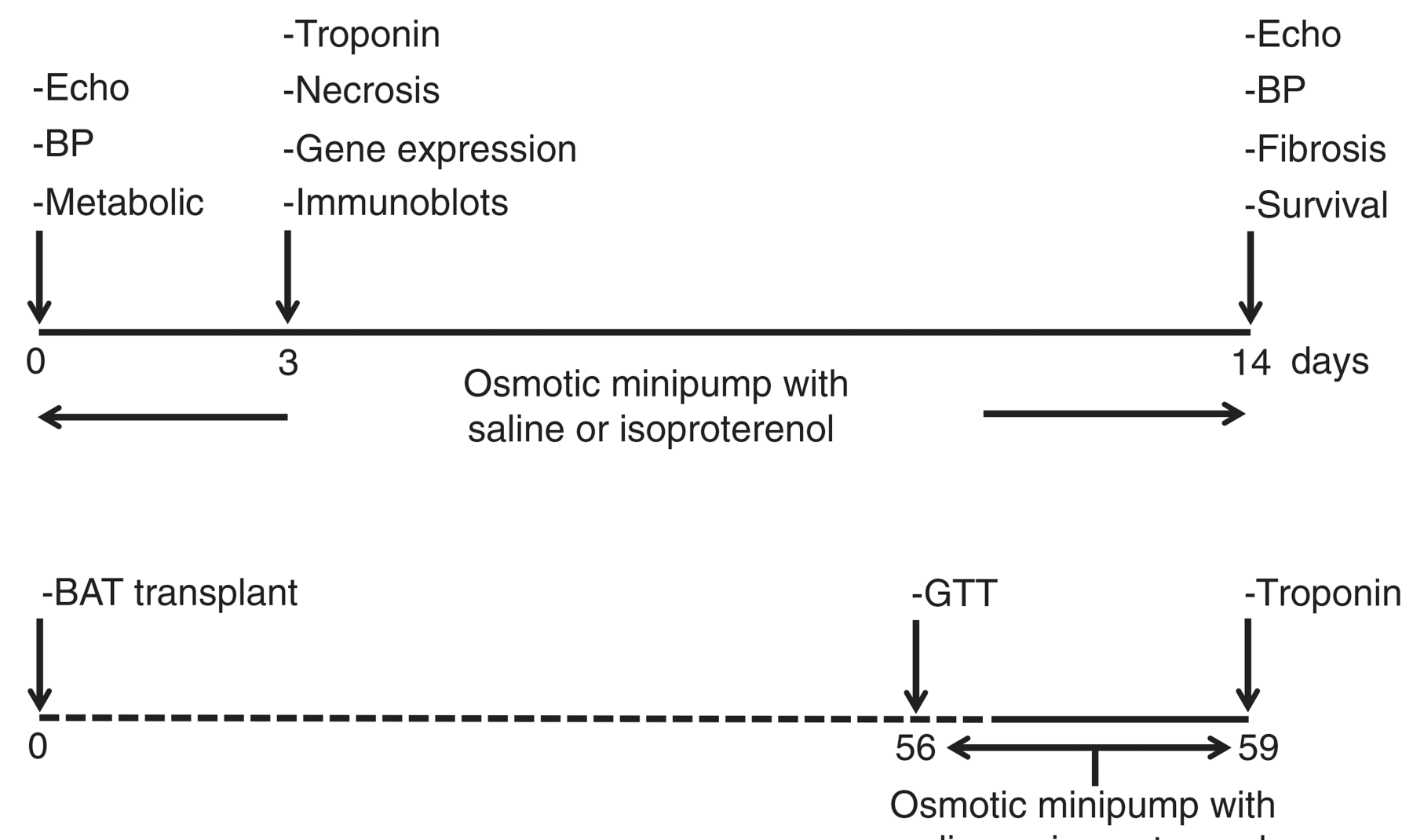

-GTT

-LAD ligation

-UCP1 mRNA<smiles>CCOCCO</smiles>

Osmotic minipump with saline or isoproterenol

Fig. 1.

Flow chart of experimental procedures. 
A

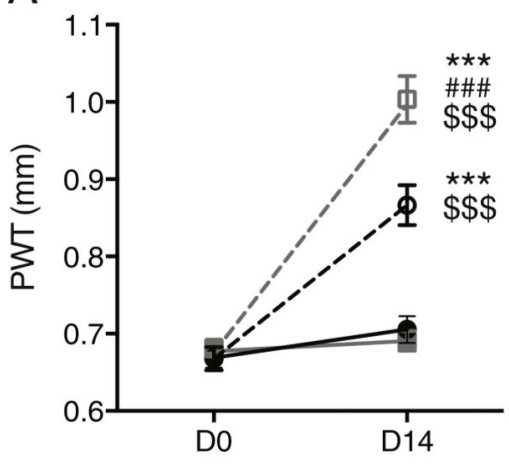

C

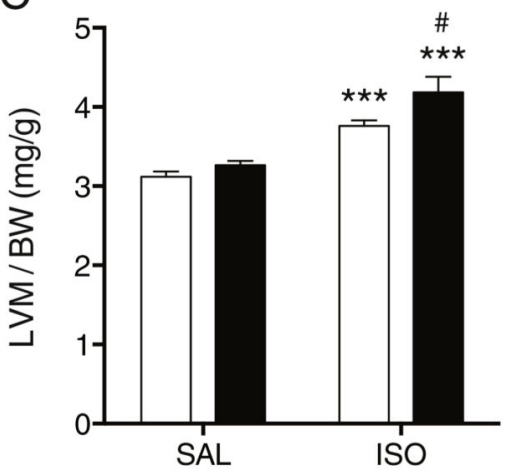

$\square$ WT

$\mathrm{KO}$

Fig. 2.
B

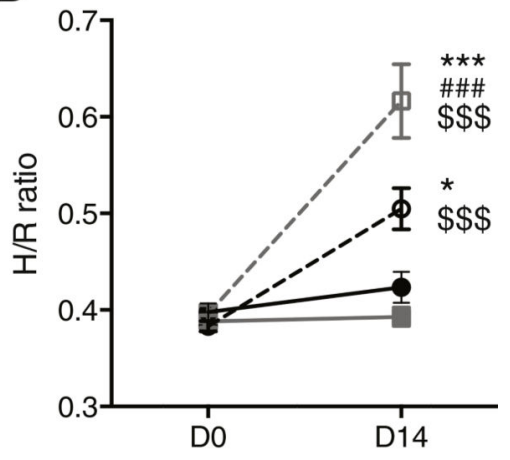

D

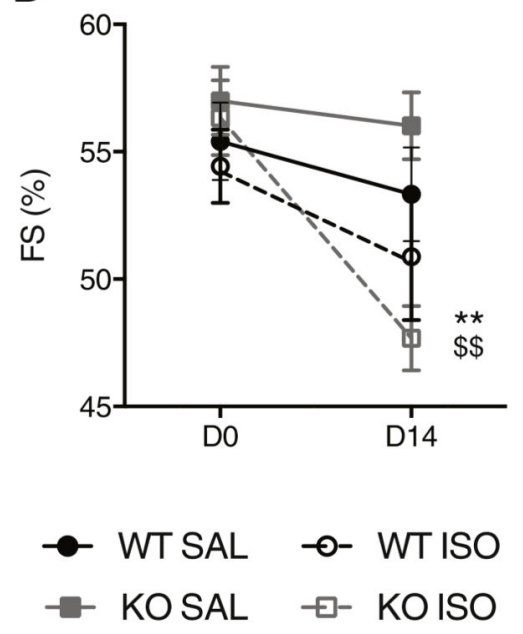

I

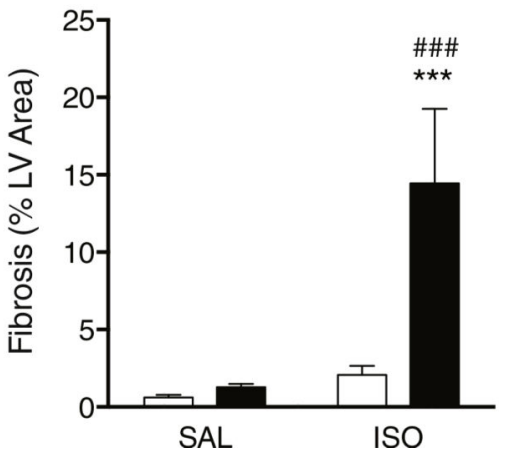

Effect of 14 days of isoproterenol infusion on echocardiographic and pathologic parameters in male $\mathrm{WT}$ and $\mathrm{UCP}^{-/-}$mice. The $\mathrm{UCP}^{-/-}$mice developed more LV hypertrophy and fibrosis than WT mice and decreased LV fractional shortening after isoproterenol. Panel A: Posterior wall thickness (PWT) measured with echocardiography. Panel B:

Echocardiographically-derived thickness/radius ratio (H/R). Panel C: Ratio of LV mass measured at necropsy to bodyweight (LVW/BW). Panel D: Echocardiographically-derived fractional shortening (FS). (Echocardiographic data acquired in WT SAL N $=6$, WT ISO N 
$=8$, KO SAL N $=11$, KO ISO N = 8) Panels E, F, G, H, I: Myocardial fibrosis detected by PicroSirius staining. Representative slices in a WT mouse (E) and $\mathrm{UCP} 1^{-/-}$mouse (G) after 14 days of saline infusion and in a WT mouse $(\mathrm{F})$ and $\mathrm{UCP} 1^{-/}$mouse $(\mathrm{H})$ after 14 days of isoproterenol infusion. Panel I: Quantification of myocardial fibrosis in WT and UCP1 ${ }^{-/-}$ mice, after 14 days of saline or isoproterenol infusion (WT SAL N $=6$, WT ISO N $=8, \mathrm{KO}$ SAL N = 5, KO ISO N = 5). *: p < 0.05; **: $\mathrm{p}<0.01$; *** $\mathrm{p}<0.001$ vs. sham (saline infusion) of the same strain at 14 days; $\$$ : $p<0.01 ; \$ \$$ : $p<0.001$ vs. baseline (D0) in the same strain; \#: $\mathrm{p}<0.05$; \#\#: $\mathrm{p}<0.001$ vs. isoproterenol in WT mice. WT: wild-type; KO: $\mathrm{UCP}^{-1-}$ mice; D0: baseline; D14: 14 days of isoproterenol; SAL: saline infusion; ISO: isoproterenol infusion. 


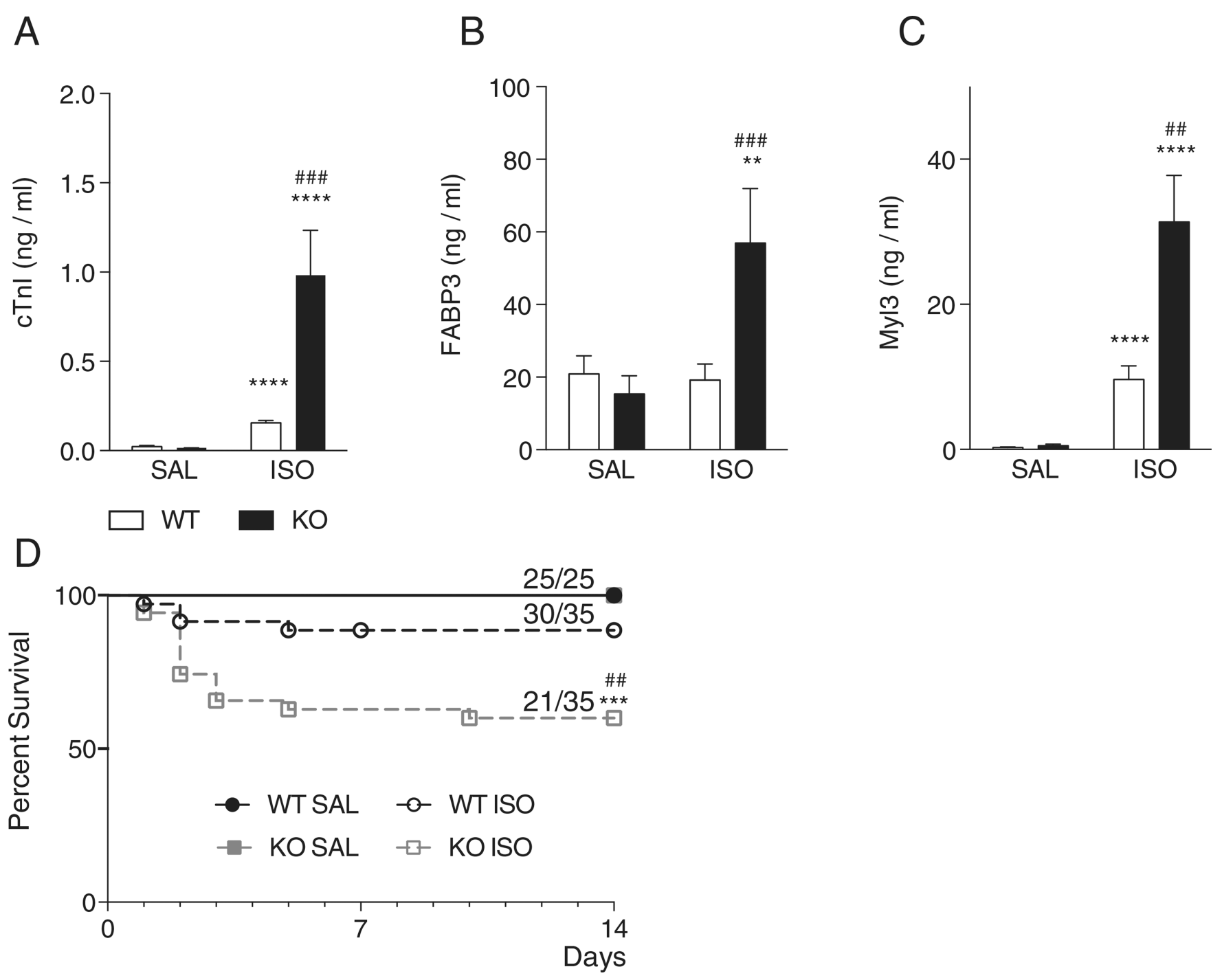

Fig. 3.

Markers of myocardial injury in $\mathrm{WT}$ and $\mathrm{UCP} 1^{-/-}$mice at 3 days and survival of WT and $\mathrm{UCP}^{-/-}$mice with saline or isoproterenol infusion after 14 days. Panel A-C: Cardiac troponin I (cTnI, Panel A), fatty acid binding protein 3 (FABP3, Panel B), myosin light chain 3 (Myl3, Panel C) were measured in EDTA plasma after 3 days of isoproterenol. Both $\mathrm{cTnI}$ and Myl3 were higher in $\mathrm{WT}$ and $\mathrm{UCP}^{-/-}$mice, however, the increase was greater in $\mathrm{UCP} 1^{-1}$ mice. FABP3 only increased in $\mathrm{UCP} 1^{-1-}$ mice. (WT SAL $\mathrm{N}=12$, WT ISO N $=12$, KO SAL N = 11, KO ISO N = 10). Panel D: Kaplan-Meier plot of survival during 14 days of follow-up in WT and $\mathrm{UCP}^{-/-}$mice after saline or isoproterenol infusion (WT SAL N = 25, WT ISO $\mathrm{N}=35$, KO SAL $\mathrm{N}=25$, KO ISO N = 35). **: $\mathrm{p}<0.01$; **** $\mathrm{p}<0.0001$ vs. saline infusion of the same strain; \#\#: $\mathrm{p}<0.01$; \#\#\#: $\mathrm{p}<0.001 \mathrm{vs}$. isoproterenol in WT mice. WT: wild-type; $\mathrm{KO}: \mathrm{UCP}^{-/-}$mice; SAL: saline infusion; ISO: isoproterenol infusion. 

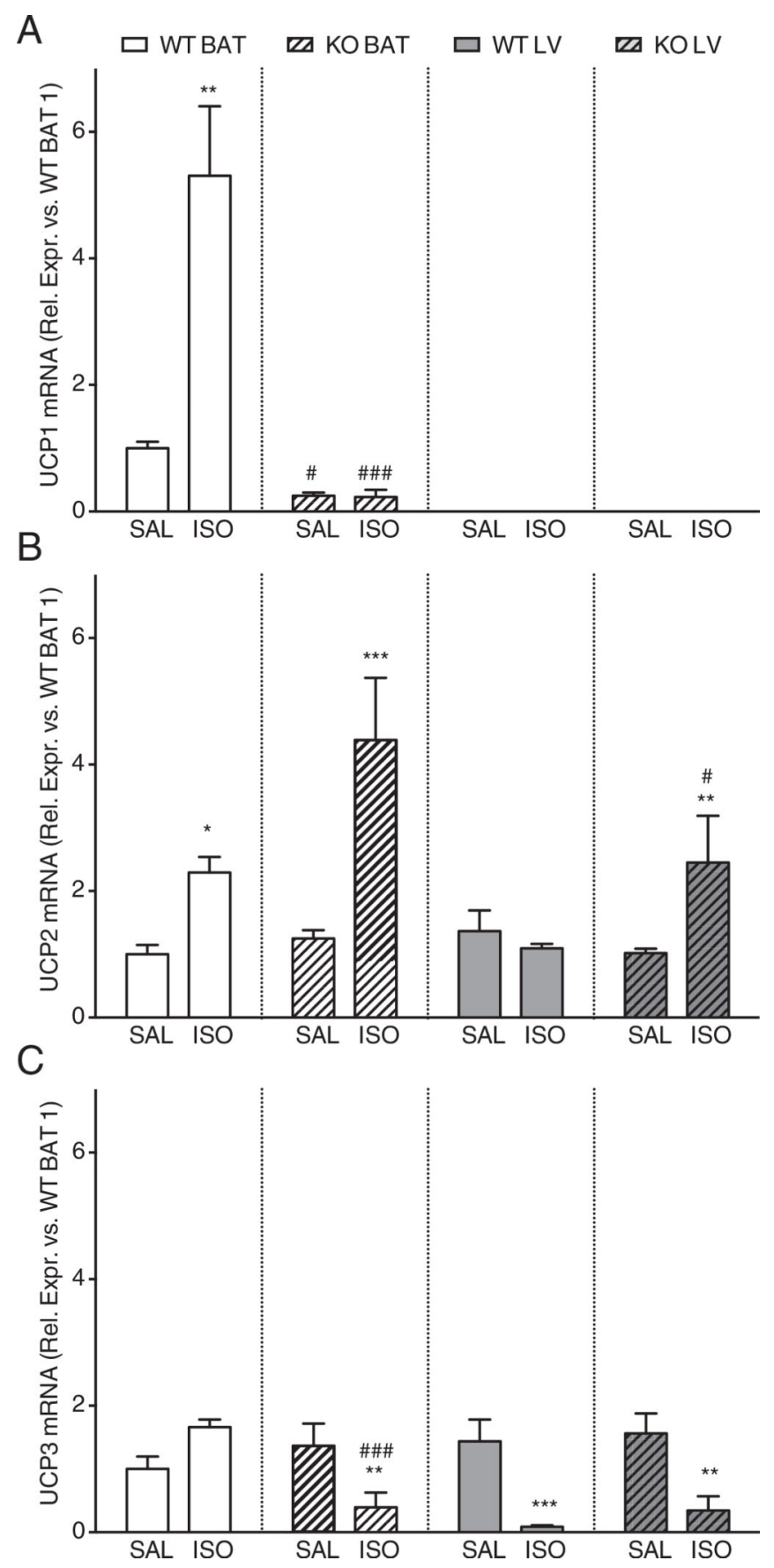

Fig. 4.

Gene expression levels of uncoupling proteins 1 (Panel A), 2 (Panel B) and 3 (Panel C) in the brown adipose tissue and left ventricle of $\mathrm{WT}$ and $\mathrm{UCP}^{-/-}$mice, after 3 days of saline or isoproterenol infusion. Panel A: UCP1 expression increased in WT BAT after isoproterenol and was not detected in the LV of WT mice. Panel B-C: No compensatory increase in the expression levels of UCP2 and 3 in BAT was noted in $\mathrm{UCP} 1^{-/}$mice. Panel $\mathrm{B}$ : Levels of UCP2 in the LV were similar between WT and UCP1 ${ }^{-1-}$ mice at baseline but in $\mathrm{UCP}^{-/-}$mice $\mathrm{UCP} 2$ in the LV was increased by isoproterenol. Panel C: The changes in 
$\mathrm{UCP} 3$ in the LV induced by isoproterenol were similar between $\mathrm{WT}$ and $\mathrm{UCP} 1^{-/-}$mice. $(\mathrm{N}$ $=6$ for all groups). $*$ : $<<0.05 ; * *: p<0.01 ; * * *: p<0.001$ vs. saline infusion of the same strain at 3 days; \#: $\mathrm{p}<0.05$; \#\#: $\mathrm{p}<0.001$ vs. same condition (saline or isoproterenol) in WT mice. WT: wild-type; KO: $\mathrm{UCP}^{-/-}$mice; SAL: saline infusion; ISO: isoproterenol infusion; BAT: brown adipose tissue; LV: left ventricle. 
A B

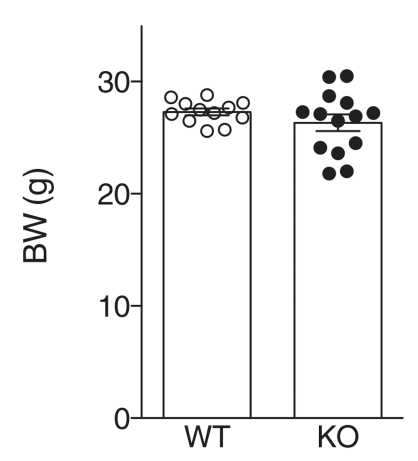

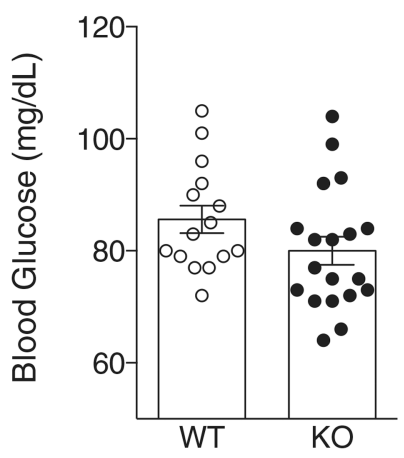

E

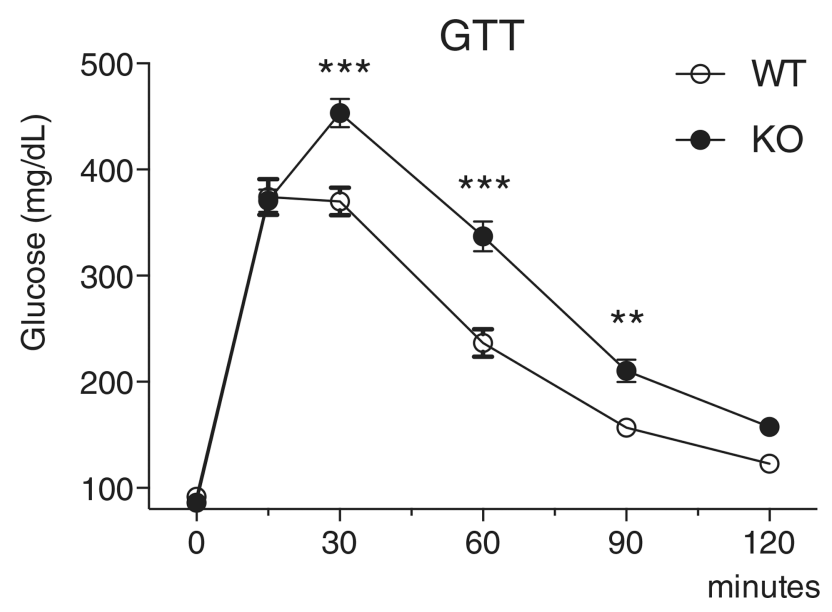

E
C

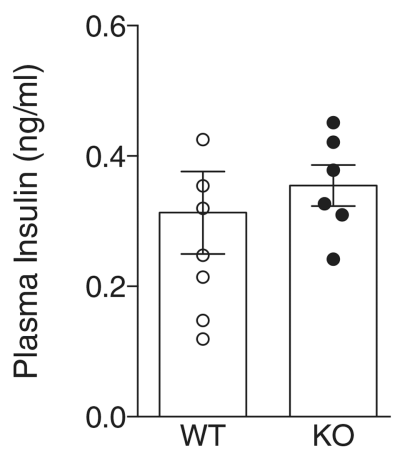

F

Fig. 5.

Body weight and metabolic parameters in $\mathrm{WT}$ and $\mathrm{UCP} 1^{-/}$mice. Panel A: Body weight of WT and $\mathrm{UCP}^{-/-}$mice (WT N $=12, \mathrm{KO} \mathrm{N}=14$ ). Panel B-D: Plasma levels of glucose (Panel B) $(\mathrm{WTN}=12, \mathrm{KON}=14)$, insulin (Panel C) $(\mathrm{WTN}=8, \mathrm{KO} \mathrm{N}=6)$ and triglycerides (Panel D) (WTN $=10, \mathrm{KON}=8)$ in mice fasted for $16 \mathrm{~h}$ were similar in the WT and UCP1 ${ }^{-/-}$mice. Panel E-F: Glucose tolerance test (WTN $\left.=12, \mathrm{KO} N=14\right)$. (Panel $\mathrm{E}$ ) and insulin tolerance test (WT $\mathrm{N}=8, \mathrm{KO} \mathrm{N}=6$ ). (Panel $\mathrm{F}$ ) in $\mathrm{WT}$ and $\mathrm{UCP}^{-/-}$mice. The UCP1 ${ }^{-l-}$ mice were glucose-intolerant, however, were not insulin resistant compared to WT mice. ${ }^{* *}: \mathrm{p}<0.01 ; * * *: \mathrm{p}<0.001$ vs. WT at the same time point. TG: triglycerides; WT: wild-type; KO: $\mathrm{UCP}^{-/-}$mice; GTT: glucose tolerance test; ITT: insulin tolerance test. 

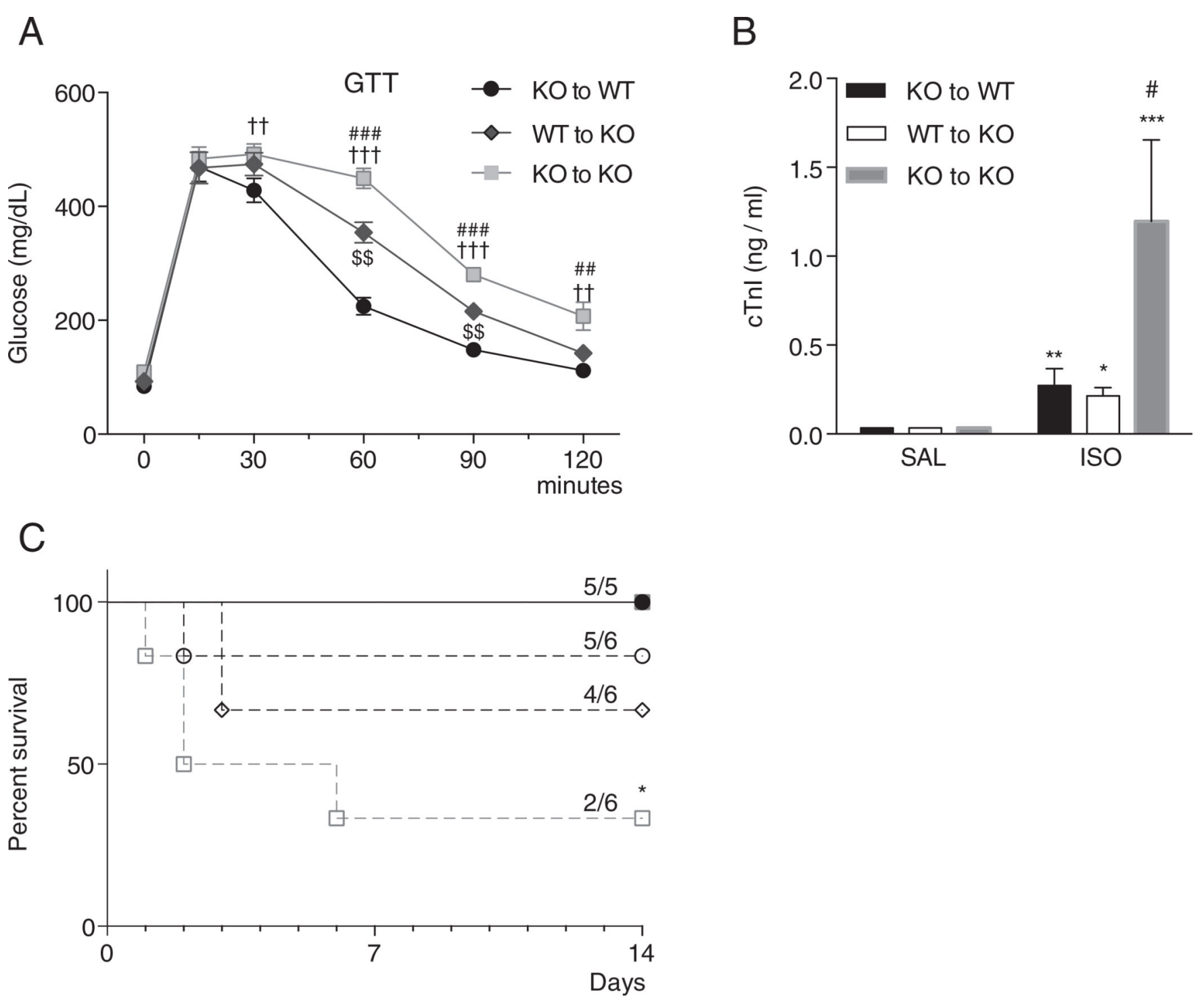

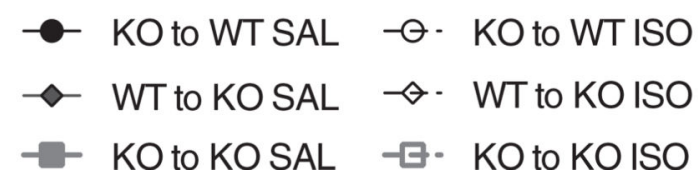

Fig. 6.

Effects of the transplantation of brown adipose tissue (BAT) on the glucose tolerance (Panel A), and plasma cardiac troponin I levels (Panel B) and survival (Panel C) after isoproterenol infusion. Panel A-B: The transplantation of WTBAT attenuated the glucose intolerance in $\mathrm{UCP}^{-/-}$mice 8 weeks post-transplantation (Panel A) $\left(\mathrm{UCP}^{-/-} \mathrm{BAT}\right.$ to $\mathrm{WTN}=10$, WT BAT to $\mathrm{UCP}^{-/-} \mathrm{N}=10, \mathrm{UCP}^{-/-} \mathrm{BAT}^{-1} \mathrm{UCP}^{-/-} \mathrm{N}=10$ ) and prevented the increased plasma cardiac troponin I level detected 3 days after isoproterenol infusion (Panel B) (UCP1 $^{-/-}$BAT to WT: SAL N = 3, ISO N = 6; WT BAT to UCP1 ${ }^{-/-}: \mathrm{SAL} \mathrm{N}=3$, ISO N = 3; $\mathrm{UCP}^{-/-} \mathrm{BAT}$ to $\mathrm{UCP} 1^{-/-} \mathrm{SAL} \mathrm{N}=3$, ISO N = 3). Panel C: Mortality was higher in $\mathrm{UCP}^{-/-}$mice transplanted with $\mathrm{UCP}^{-/-}$BAT after 14 days of isoproterenol infusion.

(SAL groups $\mathrm{N}=5$, ISO groups $\mathrm{N}=6$ ) *: $\mathrm{p}<0.05 ; * *$ : $<<0.01$; ***: $\mathrm{p}<0.001$ vs. baseline 
of the same group; \#: $\mathrm{p}<0.05$; \#\#: $\mathrm{p}<0.001$ vs. WT to KO at the same time point; $\$ \$$ : $\mathrm{p}<$ 0.01 vs. KO to WT at the same time point; $\dagger \dagger: \mathrm{p}<0.01 ; \dagger \dagger$ : $\mathrm{p}<0.001$ vs. KO to WT at the same time point: wild-type; KO: $\mathrm{UCP} 1^{-/}$mice; SAL: saline infusion; ISO: isoproterenol infusion; KO to WT: KO BAT to WT mouse; WT to KO: WT BAT to KO mouse; KO to KO: KO BAT to KO mouse. WT: wild-type; KO: $\mathrm{UCP}^{-1-}$ mice. 

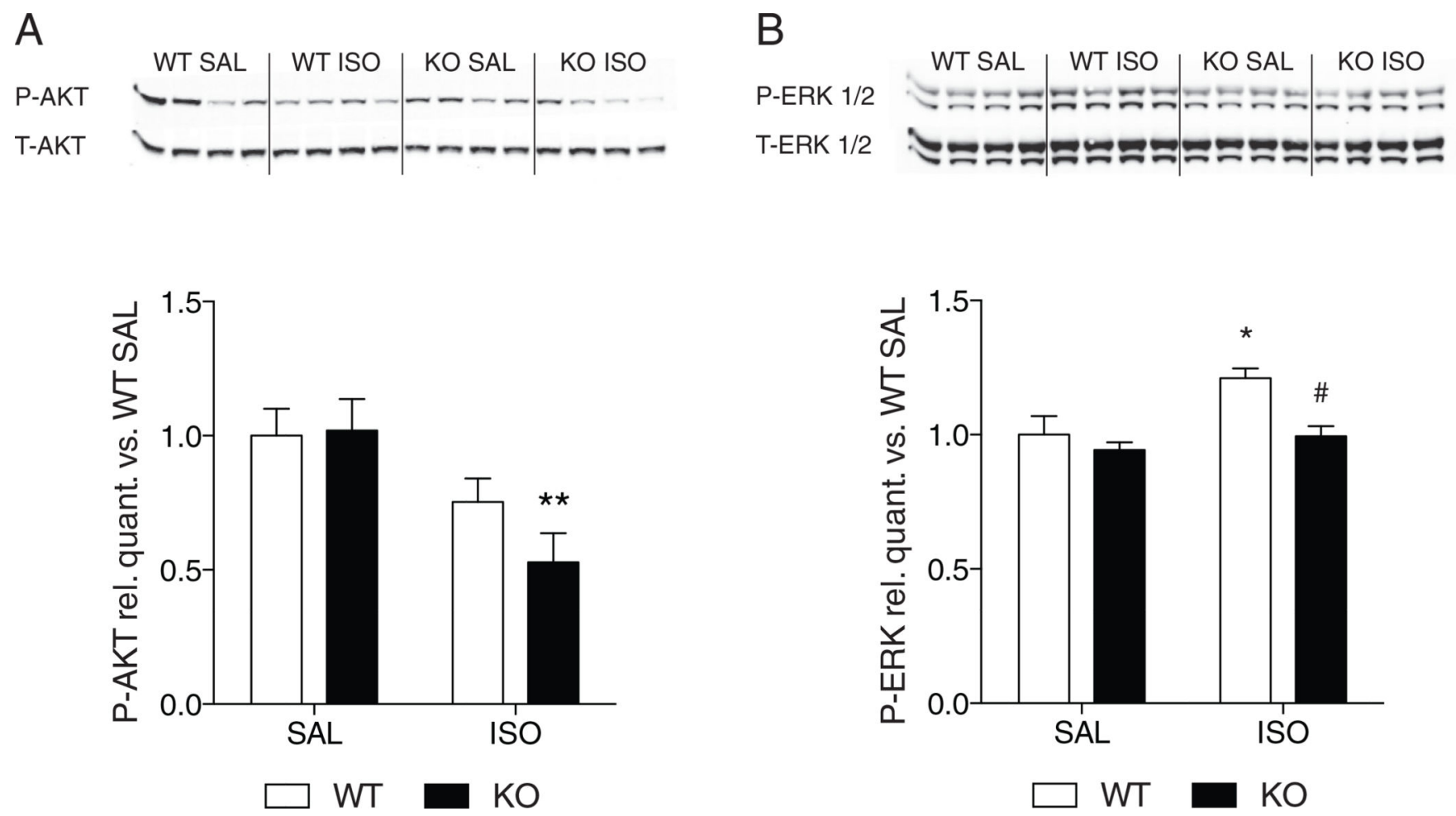

Fig. 7.

Effect of isoproterenol infusion on the phosphorylation of AKT and ERK. Panel A-B: Representative immunoblots and quantification of P-AKT on Ser473 and total AKT (Panel A) and P-ERK1/2 on Thr202/Tyr204 and Thr185/Tyr187, respectively, and total ERK 1/2 (Panel B) on LV homogenates of WT and KO mice after 3 days of saline or isoproterenol infusion. Densitometry is presented as an average of 3 technical repeats, with 4 biological repeats per group. *: $\mathrm{p}<0.05 ; * * \mathrm{p}<0.01$ vs. saline of the same group; \#: $\mathrm{p}<0.05 \mathrm{vs.}$ isoproterenol in WT mice. WT: wild-type; $\mathrm{KO}: \mathrm{UCP}^{-1-}$ mice. 

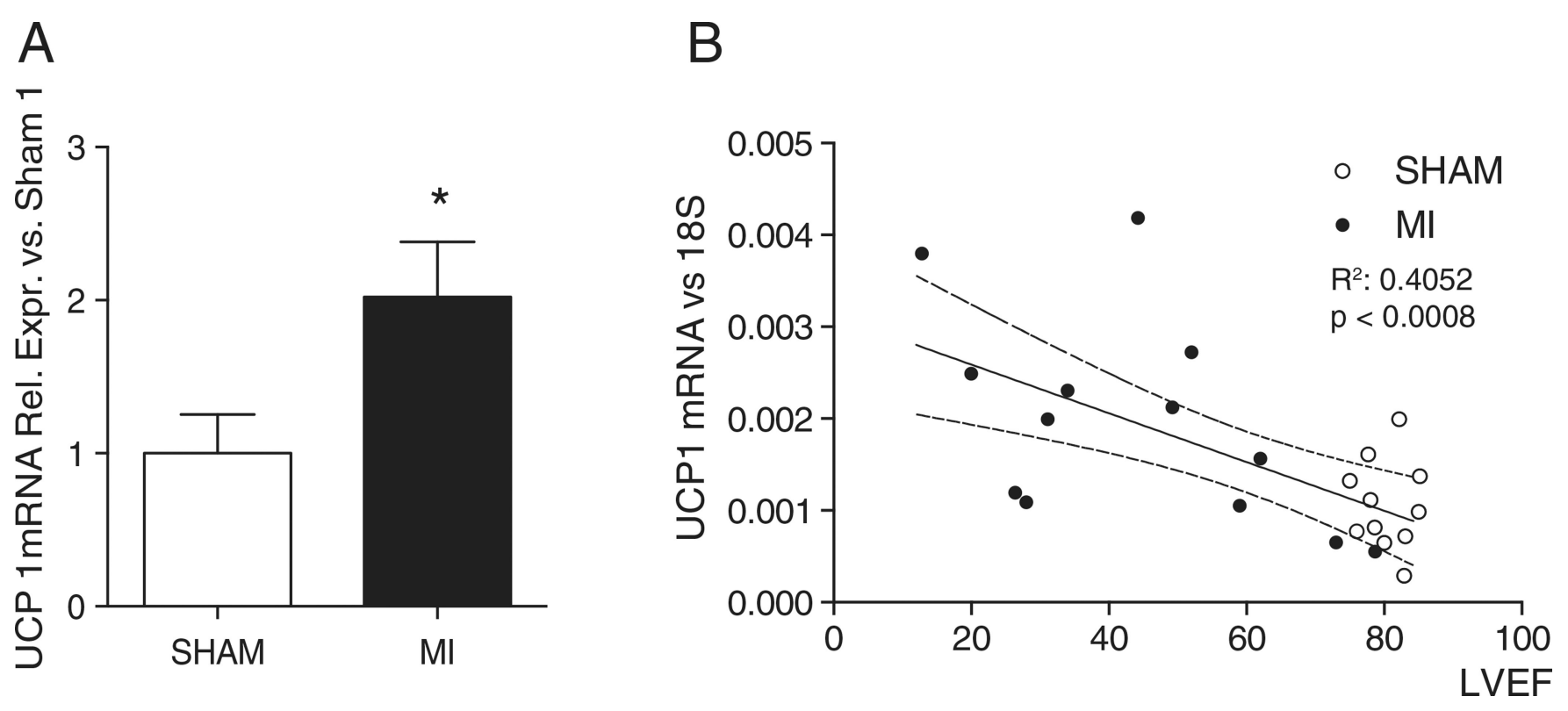

Fig. 8.

Activation of brown adipose tissue (BAT) in heart failure. Panel A: Activation of BAT, assessed by the gene expression level of UCP1, was noted 8 weeks after myocardial infarction and was correlated to the degree of LV dysfunction. Gene expression levels of UCP1 in WT mice, either sham-operated or subjected to left anterior descending coronary artery ligation (SHAM N = 11; MI N = 13). Panel B: Correlation between UCP1 gene expression levels and LV ejection fraction. The straight line represents the correlation, the dashed line the $95 \%$ confidence interval of the correlation. MI: myocardial infarction, LVEF: left ventricular ejection fraction. *: $\mathrm{p}<0.05$ vs. SHAM. 


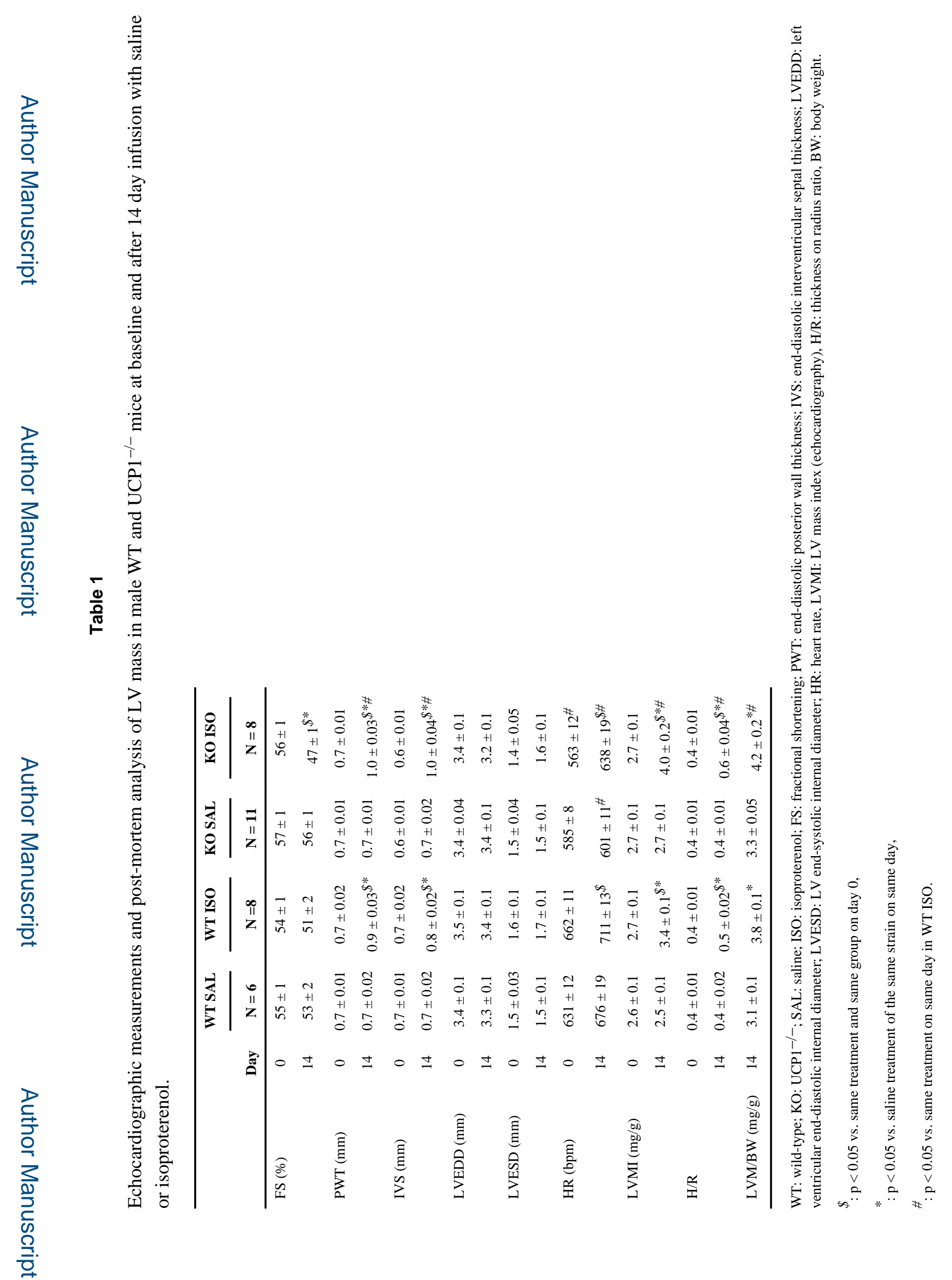

J Mol Cell Cardiol. Author manuscript; available in PMC 2016 July 01. 